\title{
AIDS-Related Kaposi Sarcoma T1 (Poor Risk): Pulmonary Involvement
}

National Cancer Institute

\section{Source}

National Cancer Institute. AIDS-Related Kaposi Sarcoma T1 (Poor Risk): Pulmonary

Involvement. NCI Thesaurus. Code C134976.

AIDS-related Kaposi sarcoma involving the lungs. 